http://dx.doi.org/10.18232/alhe.956

Artículos

\title{
La población maya yucateca en la Universidad de Yucatán: análisis socioeconómico de la exclusión, 1922-1990
}

\section{The Mayan Yucatec population at the University of Yucatan: socioeconomic analysis of exclusion, 1922-1990}

Lorgio G. Cobá1, * (DD 0000-0002-1264-698X

${ }^{1}$ Universidad Autónoma de Yucatán, Mérida, México

* Correspondencia: lorgio.coba@correo.uady.mx

Resumen. En el presente artículo se estudia el lento proceso de incorporación de la población maya yucateca a los estudios superiores. A través del uso de herramientas cuantitativas se analiza la población universitaria y se muestra que el maya yucateco inició su andar en la Universidad de Yucatán a partir de mediados del siglo pasado. El texto argumenta que a pesar de que la universidad era incluyente, existieron mecanismos de exclusión que operaron en contra del ingreso del maya yucateco a sus espacios de formación profesional, entre las más importantes están las desigualdades económicas, condiciones clave en los momentos de crisis económica, y que determinaron el éxito académico.

Palabras clave: universidad; mayas yucatecos; exclusión; apellidos; condiciones económicas.

Abstract. The present paper studies and analyzes the slow process of incorporation of the Yucatec Mayan population to higher education. The university population is analyzed through the use of quantitative tools, and it is shown that the Yucatec Maya began its presence in the University of Yucatan from the middle

CÓMO CITAR: Cobá, L. (2019). La población maya yucateca en la Universidad de Yucatán: análisis socioeconómico de la exclusión, 1922-1990. América Latina en la Historia Económica, 26(3), e956. DOI: 10.18232/alhe.956 
of the last century. The text argues that even though the university has been inclusive, there were exclusion mechanisms that operated against the income of Maya population to their vocational training spaces. Among others, the most important tools of exclusion are the economic inequalities, key conditions in times of economic crisis, and that determined academic success.

Key words: university; Mayas of Yucatan; exclusion; economic conditions.

JEL: I24; N36.

Recibido: 29 de enero de 2018.

Aceptado: 13 de julio de 2018.

Publicado: 30 de abril de 2019.

\section{INTRODUCGIÓN}

Los estudios sobre la universidad han dejado en claro que esta institución es excluyente y elitista. El nivel económico y sociocultural, género, raza y etnia son mecanismos de exclusión que amenazan el valor de la igualdad de oportunidades y la democratización del ámbito universitario (Barreyro, 2008; Bourdieu, 2013; Casillas, Chain, Jácome, 2007). El análisis de estas variables de exclusión en la población universitaria ha mejorado nuestra comprensión sobre los retos y problemas que son necesarios atender para mejorar la calidad de la educación superior en México. No obstante, las investigaciones se han abordado desde la economía, antropología, sociología e investigación educativa, por lo que se han privilegiado enfoques sincrónicos. Los estudios diacrónicos y de corte histórico empiezan a germinar.

El estudio histórico de la población universitaria se ha ocupado del periodo colonial ${ }^{1}$ Uno de los temas que la historiografía ha atendido es el de la población indígena. ${ }^{2}$ Para el siglo XIx, Ríos (2014) ha destacado los estudios hechos para el Colegio de San Gregorio como continuidad de la tradición colonial de mantener un espacio destinado para la formación de los indígenas en los estudios superiores, pero ha señalado la necesidad de ampliar el horizonte y estudiar otros espacios universitarios y regiones. En el caso del siglo xx, los análisis se centran en la movilización política estudiantil (Marsiske, 1998, 2011). Los estudios de la educación superior indígena en esta misma centuria tienen sus primeros resultados en Laura Giraudo (2010). A través de un análisis comparativo entre México y Bolivia, se ve en la Casa del Estudiante Indígena el proyecto posrevolucionario de formar indígenas, difusores de cultura, de diferentes regiones del país para que contribuyeran, desde sus lugares de origen, a incorporar al indio a la nación; pero dicho programa pronto fracasó y a mediados del siglo xx la formación de una elite intelectual indígena fue abandonada. En este contexto, y de acuerdo con Ríos (2014), podemos interrogar ¿̇cuál fue el proyecto posrevolucionario de los gobiernos estatales para la población indígena?, y ¿accedieron a otros centros de formación universitaria distintos a los creados exclusivamente para ellos? Existe un acuerdo de que a mediados del siglo xx inicia el proceso de masificación de la educación superior, aunque no

\footnotetext{
${ }^{1}$ Rodolfo Aguirre (2011) ha trabajado desde distintas temáticas y enfoques a la población universitaria de la Real y Pontificia Universidad de México en la época colonial. Sobre el caso de los colegios coloniales de Puebla, véanse Torres (2013, cap. 3), y Domínguez (2012).

${ }^{2}$ El trabajo clásico sobre la población indígena colonial en los estudios superiores: Menegus y Aguirre (2006); para el caso yucateco, Cobá (2017). La educación rural e indígena ha sido un tema atendido por la historiografía mexicana, pero aún no se ocupa de los indígenas en la universidad del siglo xx. Véase Aguirre (2016).
} 
hay consenso sobre sus causas. En Latinoamérica la matrícula creció sorprendentemente (Gallo, 2005; Levi, 1995). ¿Cuál fue el lugar de la población indígena en este proceso de masificación universitaria?

La Universidad de Yucatán (ahora Universidad Autónoma de Yucatán) es un excelente mirador para acercarse a la problemática de la inclusión de la población indígena en los estudios universitarios. Fundada en 1922 en una región con una alta tasa de población indígena, su artífice, Felipe Carrillo Puerto, construyó un proyecto de gobierno en el que los mayas eran parte esencial $\left.\right|^{3}$ ¿Estuvieron las puertas abiertas de la universidad para los mayas yucatecos?, ¿puede observarse en esta universidad, enclavada en una región indígena, una mayor apertura? Uno de los problemas que enfrenta la historiografía, y en general los estudiosos de la población indígena universitaria, es la ausencia de indicadores étnicos en los registros escolares que permitan analizarla 4 Este obstáculo puede ser superado en el caso de la Universidad de Yucatán: a diferencia de otras regiones de México, el proceso de conquista en Yucatán no borró los apellidos indígenas, de manera que estos se vuelven un indicador que nos puede ayudar a conocer la inclusión y/o exclusión de la población maya en los estudios universitarios. En este contexto, el presente estudio ofrece un análisis del itinerario seguido por la población maya yucateca rumbo a la universidad; con un enfoque cuantitativo muestra el lento proceso de incorporación de la población indígena a los estudios universitarios.

\section{LA POBLACIÓN MAYA YUCATECA EN EL SIGLO XX}

Cook y Borah (1998, pp. 126-133) han mostrado que desde mediados del siglo xix la población yucateca inició un crecimiento positivo. Pero un incremento significativo se observa durante las primeras siete décadas del siglo xx (1910-1970): la población se duplicó. Según estimaciones de Marie Lapointe y Lucie Dufresne (1990, pp. 360-361 y 364-365), en el periodo intercensal de 1930 a 1940 la población del estado aumentó $8 \%$, pero las zonas productivas crecieron de manera distinta: la zona henequenera $3.4 \%$, en tanto la región este y sureste del estado, la zona ganaderomaicera, creció a un ritmo mayor ( 16 y $22 \%$, respectivamente).

Los estudios demográficos demuestran que, a partir de la década de 1940, las tasas de mortalidad mexicana disminuyeron; el descenso de los niveles de mortalidad empezó a ser significativa a partir del bienio de 1922-1924, y para mediados de los sesenta se redujo a un dígito. Paralelo a la disminución de la tasa de mortalidad, se experimentó un aumento en la esperanza de vida. Siguiendo los patrones nacionales, se observa que, desde 1950, el estado de Yucatán se encuentra entre las entidades del país con menor índice de mortalidad infantil, y para la década de 1980 entre los más bajos. El combate a las principales enfermedades (paludismo, tosferina, viruela y sarampión) explica este comportamiento de las tasas de mortalidad (Rabell y Mier y Terán, 1986), y ayuda a comprender el incremento de la población en la segunda mitad del siglo xx. Particularmente a partir de 1980, cuando la dinámica económica de la capital yucateca, Mérida, la convierta en un polo de atracción de mano de obra en busca de oferta de empleo que la industria henequenera dejó de ofrecer (Ramírez, 1993, pp. 11-12).

\footnotetext{
${ }^{3}$ Sobre Carrillo Puerto y su proyecto educativo véase Sandoval y Mantilla (1994, pp. 109-136). En sentido estricto nuestra tradición historiográfica sólo cuenta con estudios que enlistan parcialmente a la población en los estudios superiores en la época colonial, véanse Baqueiro (1894) y Arrigunaga y Peón (1975).

${ }^{4}$ Sobre los avances de la educación superior y los problemas de cuantificación véanse Zapata (2009) y Schmelkes (2013).
} 
Por otra parte, en cuanto a la composición étnica de la población, el censo de 1920 reconoció a Yucatán como uno de los "estados en donde los descendientes de la raza aborigen se han conservado en gran número", lo anterior permite argüir que a principios del siglo xx Yucatán era eminentemente indígena. En su distinción de la población, el censo clasificó a los yucatecos en tres grupos étnicos, a saber: "raza maya, mezclada o mestiza y blanca" (México. Departamento de Estadística Nacional, 1928, p. 14). De acuerdo con Cook y Borah (1998, pp. 126-131), después de la independencia se eliminaron los marcadores socioeconómicos de los registros de población que proporcionaban información de la composición étnica de la sociedad mexicana del siglo xx; a pesar de ello, para el caso de Yucatán -señalan-, en el censo de 1921 (México. Departamento de Estadística Nacional, 1928), se echó mano de una escueta pregunta para indagar el origen étnico y se emplearon "signos de pobreza" para determinar la filiación étnica; es decir, población indígena era sinónimo de pobreza. En efecto, en el censo de 1921 se usaron dos indicadores para clasificar a la población de acuerdo con su origen étnico: la adscripción y la lengua. Aunque esta última fue la de mayor peso, pues como reveló el redactor del informe final del censo, en 1921 se registraron 155155 habitantes de la raza indígena, sin embargo, los hablantes de lengua maya fueron 210 000, de donde dedujo "que existe un mayor número de indígenas del que acusa el censo, puesto que los indígenas tienen muy arraigada la conservación de sus idiomas primitivos”. Queda patente el indicador de la lengua como un atributo de la filiación étnica.

De acuerdo con Alan Knight (2013), a principios del siglo xx las características que permitían definir al indio mexicano iban más allá de los rasgos biológicos (idioma, vestido, religión, organización social, cultura y conciencia). Sin embargo, observa que el término indio no deja de ser un problema de categorización étnica y de diferentes puntos de partida para la definición. Así, por ejemplo, por un lado, el agente encargado del censo basa sus criterios en el lenguaje, y, por el otro, los voceros indigenistas no oficiales prefieren una categoría india más amplía e incluyente, que refleja posiciones políticas más generales. Por otra parte, la misma concepción de indígena está sujeta al carácter subjetivo de dicho término, pues depende de muchas características percibidas. Estas perspectivas se pueden sintetizar en dos líneas: "la percepción intrínseca del individuo o la comunidad, por una parte, y la percepción extrínseca del observador" (pp. 54-57).

Consideramos que es necesario establecer un punto intermedio para conciliar los extremos de las dos posturas. Parafraseando la definición de etnia de Anthony Smith (2004, pp. 27-29, 131-133), un grupo étnico, como es el caso de los mayas yucatecos, lo podemos definir como aquella comunidad que tiene un nombre propio y "comparten uno a más atributos culturales, por regla general la lengua y costumbres”, y que tiene o cree tener vínculos con un territorio, estas categorías se ven o atribuyen desde fuera, es decir, se considera que la posee, aunque la misma comunidad no se identifique como tal. En ese sentido, sin duda que la población maya yucateca de mediados del siglo xx es un grupo étnico que comparte una lengua y costumbres, que aunque no se autoidentifica como maya ${ }_{5}^{5}$ el observador externo revela su presencia. El que fuera rector de la Universidad de Yucatán, Jesús Amaro Gamboa (1988, cap. 2), en su uayeismo distingue con claridad a ese otro, a ese maya yucateco que a pesar de sus esfuerzos por difuminarse en la sociedad su lenguaje, vestimenta y cultura lo delatan.

\footnotetext{
${ }^{5}$ Sobre los distintos modos de identificarse del maya yucateco, aunque con controvertidos resultados, véase Bracamonte (2007, pp. 220-233).
} 
A pesar de los problemas por identificar al maya yucateco y otros grupos étnicos en el ámbito nacional, los datos censales de 1940 muestran un interés por registrar a los tres grupos étnicos reconocidos desde finales del siglo xix: indios o indígenas, mestizos y blancos. Lo que importa destacar es que a pesar de que las autoridades nacionales de aquel momento mostraban un discurso libre de distinción étnica, lo cierto es que este documento oficial aún tenía el interés por mantener las barreras raciales. Los atributos empleados para definir la pertenencia étnica eran de dos tipos: intrínseco o "desde adentro" (lengua) y extrínseco o "desde afuera" (la indumentaria). Aunque el de mayor peso es la lengua, y para completar el perfil étnico se emplea la indumentaria: el tipo de calzado (huaraches y zapatos) y la vestimenta. En los censos subsecuentes $(1950,1960,1970)$ varios de estos atributos no fueron indagados, únicamente se conservó la lengua. En la gráfica 1 podemos observar el comportamiento de la población indígena (monolingües y bilingües) y la población no indígena (habla sólo español).

$\mathrm{El}$ indicador que predominó en los censos para definir a la población indígena y no indígena es la lengua, indicador que permite observar su comportamiento a lo largo del periodo de estudio (véase gráfica 1). Por tal razón, en el primer universo (población maya) se incluye a los monolingües y bilingües, es decir, a los propiamente llamados indígenas y a los mestizos; esta metodología supone contabilizar a personas que no se consideran mayas (intrínseco); pero dejar fuera a todos los bilingües supone excluir del cómputo a un gran número de personas con orígenes mayas que han adoptado el idioma español, pero que continúan hablando su lengua materna.

Hasta mediados del siglo xx la proporción de la población yucateca que habla lengua maya es similar a la que tiene el español como lengua materna, es decir, mestizos e indígenas guardaban una proporción similar a los blancos. A partir de la década de 1960 se experimenta un crecimiento significativo de la población que habla únicamente español, por lo que se podría argumentar una disminución de la población maya. Sin embargo, es preciso anotar que la tendencia de los monolingües y bilingües mayas no es el descenso; al contrario, conserva una tendencia de crecimiento positivo (véase gráfica 1). En números absolutos, desde 1920 se registra una cifra superior a 150000 habitantes maya hablantes (monolingües y bilingües) en el estado; para la década de 1990 esta población se había duplicado. Si bien es cierto que en la década de 1960 se observa un ligero estancamiento, a partir del siguiente año censal (1970) experimenta un crecimiento positivo que continúa hasta la década de 1990, año en el que se registraron más de 450000 monolingües y bilingües mayas yucatecos. Por tanto, en términos generales podemos señalar que ambas poblaciones crecieron, sólo que en diversas proporciones, y la población no indígena (no hablante de lengua maya) fue la más dinámica (véase gráfica 2 ).

Desde la década de 1940 la población monolingüe entra en franco proceso de reducción, aunque en la década de 1960 experimenta un pequeño repunte, no alcanza los niveles iniciales, y para 1990 la tendencia se hace mucho más negativa. En contraste, la población bilingüe muestra un crecimiento sostenido desde la década de 1950; movimiento ascendente que dibuja una brecha que se amplía de manera significativa en la década de 1990. De acuerdo con este comportamiento, en el siglo xx se cristalizó el viejo anhelo de los liberales del siglo xIx, el porfiriato y la posrevolución: crear una nación unificada por el lenguaje (Acevedo, 2011, pp. 431-460), ya que la población maya monolingüe iba en franco descenso, pero la bilingüe en ascenso (véase gráfica 3 ).

Durante las tres décadas posteriores a 1920 la población monolingüe experimentó una tasa de crecimiento negativa, es decir, esta población decreció en relación con los periodos intercensales anteriores (1930, 1940, 1950). En 1960 existe un pequeño repunte, para luego recuperarse en la década de 1980 y caer en una nueva tendencia desfavorable en 1990. En contraste, la población 
GRÁFICA 1. POBLACIÓN INDÍGENA Y NO INDÍGENA EN YUCATÁN, 1920-1990

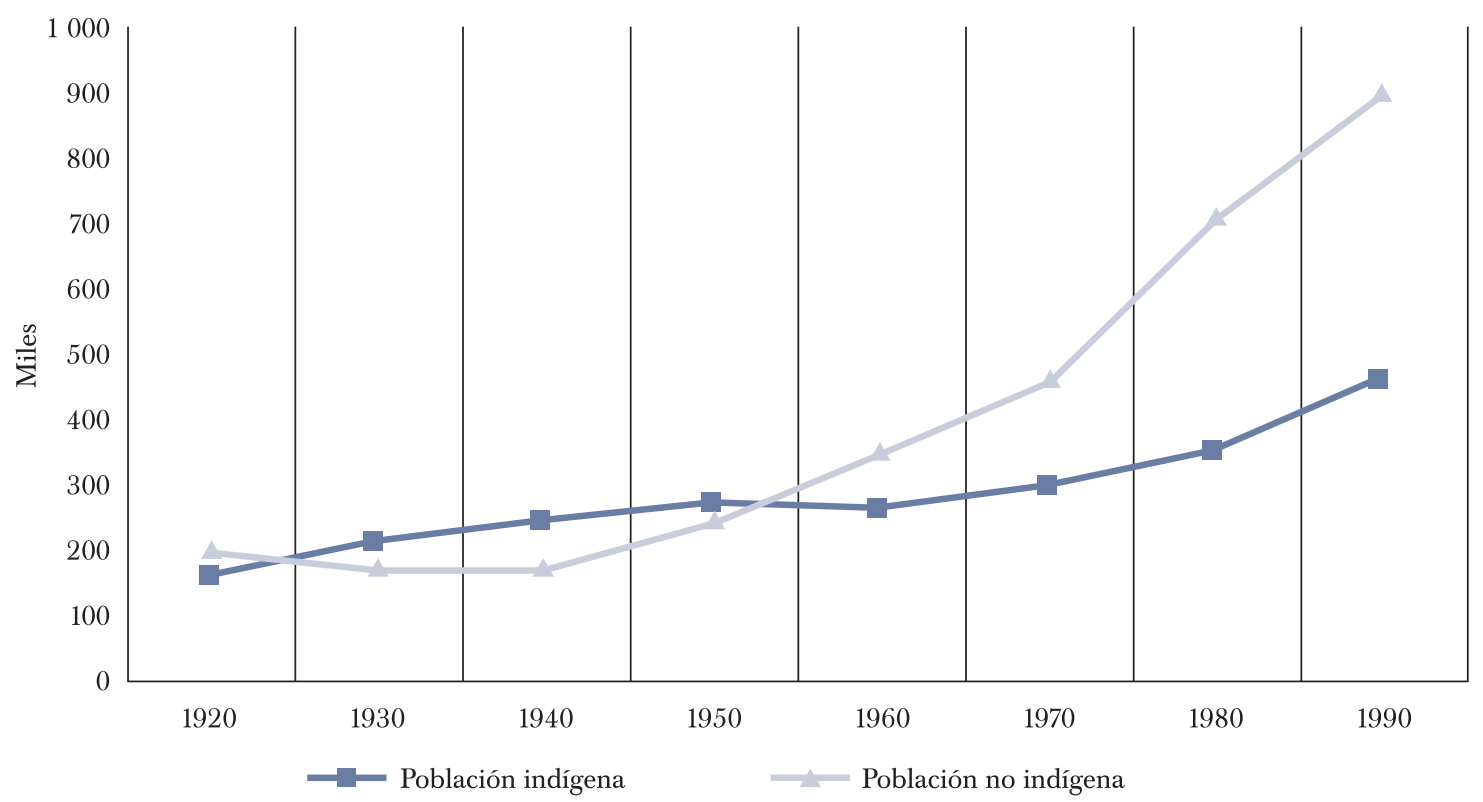

Fuente: elaboración propia con base en México. Departamento de Estadística Nacional (1928), México. Dirección General de Estadística (1934, 1943, 1953, 1963, 1971), México. Instituto Nacional de Estadística, Geografia e Informática [INEGI] (1983). Recuperado de http://www.inegi.org.mx/

bilingüe muestra un crecimiento positivo desde la década de 1940 y entra en un proceso acelerado en las tres últimas décadas del siglo xx. En suma, durante las primeras ocho décadas del siglo xx la población yucateca creció sostenidamente. En los albores del siglo xx la composición étnica de la población indica que Yucatán era eminentemente maya, con el transcurrir de los años se asiste a una transición étnica de población que se ve reflejada en el incremento de la población que únicamente habla español; sin embargo, a pesar del crecimiento menos dinámico de la población maya (monolingües y bilingües), esta continuó aumentando constantemente, aunque la más favorecida fue la bilingüe: el proceso de castellanización rindió buenos dividendos.

En la historiografía sobre la educación es un lugar común la idea de que el acceso de los indígenas a los espacios de educación formal encontró un fuerte obstáculo en la lengua. Nuestras cifras revelan que las políticas de castellanización entre la población maya rindieron buenos frutos, pues para la década de 1980 la población maya bilingüe es superior a la monolingüe; pero ambas son menor en relación con la que habla únicamente español. ¿Fue esta adquisición del lenguaje la puerta que permitió el ingreso de los mayas yucatecos a los estudios superiores? Sin duda que la respuesta a esta interrogante se vuelve crucial para calibrar las políticas de inclusión de la Universidad de Yucatán. El análisis de población revela la importancia de la etnia maya en el estado, ¿la importancia numérica de los mayas yucatecos se corresponde con un mayor acceso a los estudios universitarios? 
GRÁFICA 2. POBLACIÓN MONOLINGÜE Y BILINGÜE EN YUCATÁN, 1920-1990

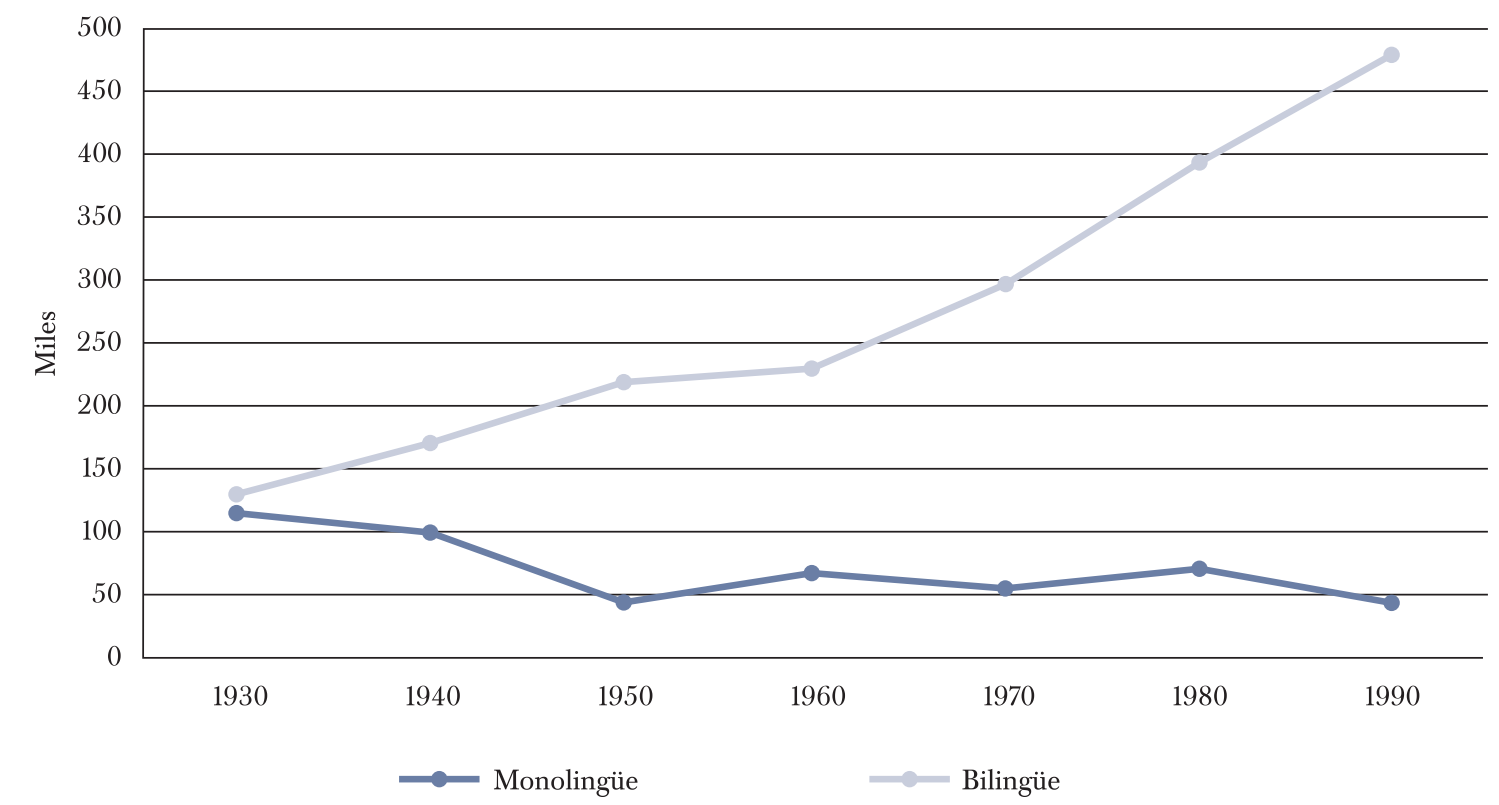

Fuentes: elaboración propia con base en México. Departamento de Estadística Nacional (1928), México. Dirección General de Estadística (1934, 1943, 1953, 1963, 1971), México. INEGi (1983). Recuperado de http://www.inegi.org. $\mathrm{mx} /$

\section{LA POBLACIÓN UNIVERSITARIA: UNA MIRADA PANORÁMICA}

Antes de pasar a analizar la población maya en los estudios universitarios, revisemos algunas cifras de la población total en los estudios superiores de la Universidad de Yucatán. ${ }^{6}$ De acuerdo con las primeras cifras estadísticas reunidas después de concluir el primer año de actividades de la Universidad Nacional del Sureste, febrero de 1923, los estudios superiores fueron ofrecidos en cinco facultades: Medicina y Cirugía, Jurisprudencia, Medicina Homeopática, Química y Farmacia e Ingeniería. A los cursos impartidos en estas aulas asistieron 169 alumnos. De esta primera generación cabe destacar que más de $50 \%, 73$ alumnos: 7 se matriculó en la Facultad de Ingeniería, lo que muestra la articulación entre la política de industrialización que impulsaba el gobierno socialista de Carrillo Puerto y la universidad; esta última tenía clara la idea de formar a los hombres-rueda para impulsar la industrialización de la economía yucateca, un aspecto contrario a la idea destacada por la historiografía de la política agrarista de Carrillo Puerto (Spencer, 1990). Al siguiente año, la universidad reportó estadísticas en los meses de julio, septiembre y noviembre sobre el movimiento escolar en las facultades. El número de instituciones que ofrecieron estudios superiores se incrementó en dos; fueron abiertas la Facultad de Medicina Alopática y la Escuela de Odon-

\footnotetext{
${ }^{6}$ Los conceptos de universidad y estudios superiores se usarán con el mismo significado. En nuestro periodo de estudio, la actual Universidad Autónoma de Yucatán tuvo otros nombres: Universidad Nacional del Sureste (1922) y Universidad de Yucatán.

${ }^{7}$ Universidad Nacional del Sureste. Sección de estadística. Año escolar 1922-1923. Boletín, 2(6), anexo, 1923.
} 


\section{GRÁFICA 3. TASA DE CRECIMIENTO DE LA POBLACIÓN MAYA MONOLINGÜE Y BILINGÜE, 1930-1990}

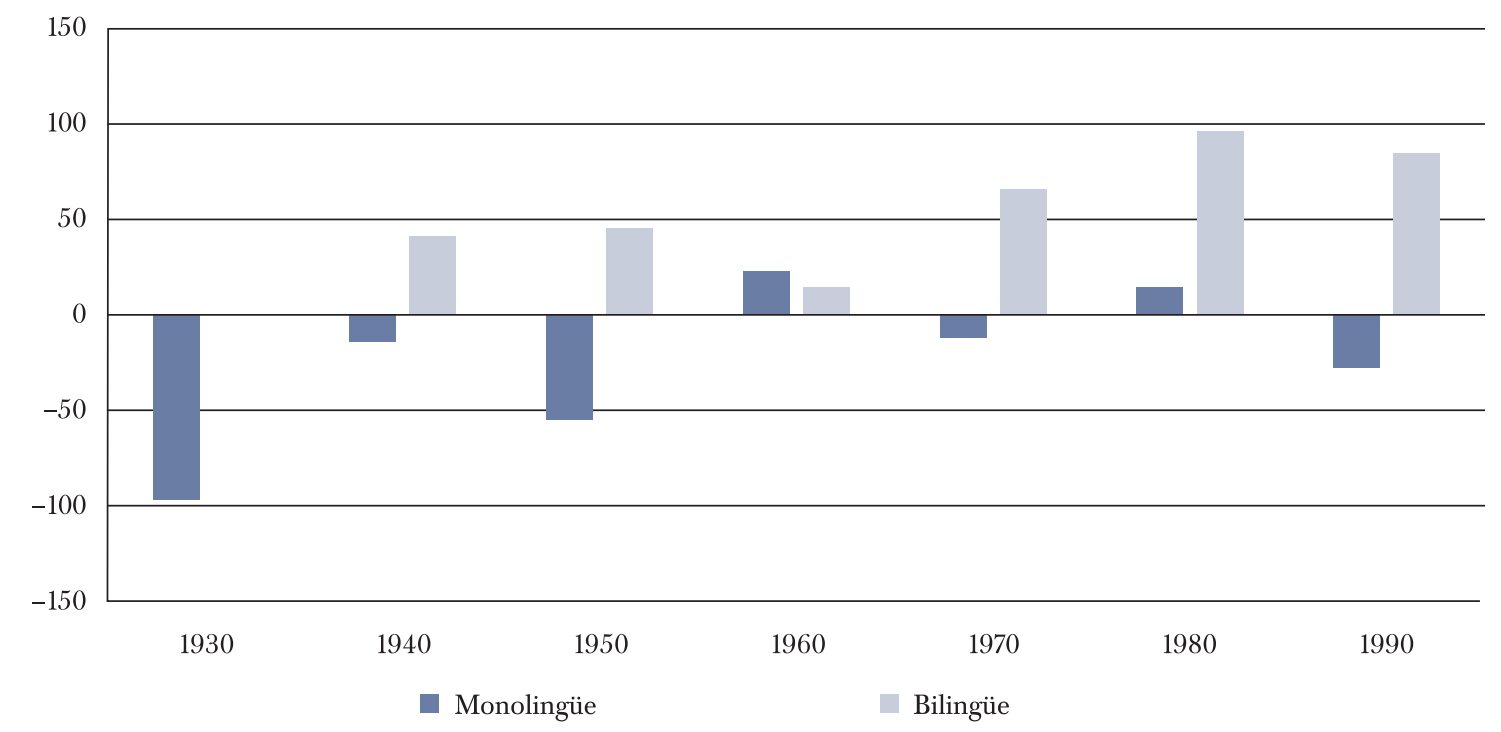

Fuentes: elaboración propia con base en México. Departamento de Estadística Nacional (1928), México. Dirección General de Estadística (1934, 1943, 1953, 1963, 1971), México. INEGi (1983). Recuperado de http://www.inegi.org. $\mathrm{mx} /$

tología. A diferencia de la estadística anterior, el número de alumnos inscritos en el último mes reportado, noviembre, fue de 118. Importa destacar que la cifra de alumnos de Ingeniera tan sólo fue la tercera parte de la registrada en febrero de 1923.

No contamos con cifras seriadas que nos muestren el movimiento sistemático de la población universitaria, pero hemos encontrado algunos datos que nos pueden indicar una tendencia durante las siguientes cuatro décadas. En cuanto al número de facultades y escuelas, continuaron las fundadoras: Medicina, Jurisprudencia, Ingeniería, Odontología y Farmacia (Química); a estas se unió Ingeniería Química (1958). A diferencia del casi nulo crecimiento de la oferta educativa, la población universitaria muestra un aumento positivo. Pero el crecimiento de las matrículas por facultades o profesiones fue distinto al proyectado en su fundación (véase cuadro 1 ).

A poco más de una década de la fundación de la universidad en 1937, la población había crecido $93 \%$, es decir, prácticamente los estudiantes inscritos se duplicaron. En el siguiente decenio, 1948, se observa una desaceleración del incremento de la matrícula, al registrarse $75 \%$ de aumento respecto al año inicial, 1937. A principios de la década de 1960, el nivel de crecimiento es menos dinámico al experimentar un cambio positivo de $26 \%$. En términos generales, podemos señalar que, durante las primeras cuatro décadas de vida de la Universidad Nacional del Sureste el crecimiento de la población fue un tanto discreta, si bien durante todos estos años apreciamos un desplazamiento positivo, al mediar el siglo xx se había desacelerado.

En cuanto a la oferta educativa, fue la misma durante casi medio siglo. La distribución de la población estudiantil por facultades muestra las preferencias de los estudiantes o la política favorecida por la universidad en la formación profesional. La Facultad de Medicina encabeza la lista al registrar, durante las cuatro primeras décadas, los mayores porcentajes de alumnos inscritos para 
CUADRO 1. POBLACIÓN UNIVERSITARIA, 1924-1962

\begin{tabular}{lrrrrrrrr}
\hline Facultades & 1924 & Porcentaje & 1937 & Porcentaje & 1948 & Porcentaje & 1962 & Porcentaje \\
\hline Medicina & 51 & 43 & 96 & 42 & 250 & 62 & 266 & 53 \\
Jurisprudencia & 37 & 31 & 90 & 39 & 36 & 9 & 66 & 13 \\
Química & 5 & 4 & 26 & 11 & 49 & 12 & 56 & 11 \\
Ingeniería & 23 & 19 & 6 & 4 & 39 & 10 & 82 & 16 \\
Odontología & 2 & 3 & 10 & 4 & 26 & 7 & 33 & 7 \\
Total & 118 & 100 & 228 & 100 & 400 & 100 & 503 & 100 \\
Tasa de & & & $93 \%$ & & $75 \%$ & & $26 \%$ & \\
$\quad$ crecimiento & & & & & & & & \\
\hline
\end{tabular}

Fuentes: Boletín, 4(6), 1924; Orbe, 1938, 1949; Universidad Autónoma de Yucatán (1985).

cursar la carrera de médico cirujano, de 40 y 60 \% (véase cuadro 1). Jurisprudencia mantuvo los mismos porcentajes durante la primera década, pero posteriormente su crecimiento es errático. Química y Odontología mantuvieron porcentajes similares. En el caso de la Facultad de Ingeniera, después de aquel proyecto industrializador de los primeros años, para 1937 la matrícula se había reducido significativamente; aunque en los siguientes años creció el número de estudiantes, no alcanzó el porcentaje de los primeros años. La Universidad de Yucatán favoreció la formación de la carrera de Medicina durante las cuatro primeras décadas del siglo xx. La carrera de Jurisprudencia quedó rezagada o fue poco demandada. La formación de ingenieros fue prácticamente abandonada, quizá reflejo del tardío proceso de industrialización del estado, que aun en la década de 1960 dependía del monocultivo henequenero y de una protoindustria reducida a abastecer el mercado local (Vera, 1990, pp. 438-441).

A partir de mediados de la década de 1960 iniciaría un crecimiento tanto de la oferta educativa como de estudiantes; un movimiento ascendente que coincide con el crecimiento positivo de la población (véase gráfica 4 ).

Durante la década de 1960 hubo un crecimiento discreto de la población universitaria, pero esta tendencia se modificó a partir de 1966, momento en que se duplicó el número de alumnos en las distintas facultades (véase gráfica 4). Desde aquel año iniciaría una tendencia ascendente que tendrá un pequeño estancamiento entre 1982 y 1984; pero a casi dos décadas (1965-1984) los estudiantes eran siete veces más, al registrar cerca de 7000 universitarios. Aquel estancamiento puede ser explicado por la crisis económica (agotamiento del modelo de sustitución de importaciones que condujo a la crisis de deuda externa y fiscal) que atraviesa el país en esos años y que impacta en el crecimiento de la economía y que provoca una reducción permanente del gasto nacional en educación (1982-1988); aquella coyuntura económica tuvo efectos negativos sobre la economía local que empezaba a romper su dependencia de la industria henequenera (Flores, 2010, pp. 61-71; Lapointe, 2006, pp. 202-228; Mungaray y Torres, 2010, pp. 9-10).

Pero también este aumento siguió el ritmo de la explosión demográfica y el acelerado proceso de urbanización experimentados a nivel nacional (Brambila, 1992, pp. 127-138), crecimiento de población del que Yucatán no se vio exenta y que inicia en 1960, pero que se acentúa entre 1970 y 1980 gracias al fenómeno migratorio interno y al cambio de perspectiva de los gobiernos estatales de impulsar la educación para favorecer el desarrollo económico (Campo y Salcines, 2008). Pe- 


\section{GRÁFICA 4. POBLACIÓN EN LAS FACULTADES DE LA UNIVERSIDAD DE YUCATÁN, 1960-1993}

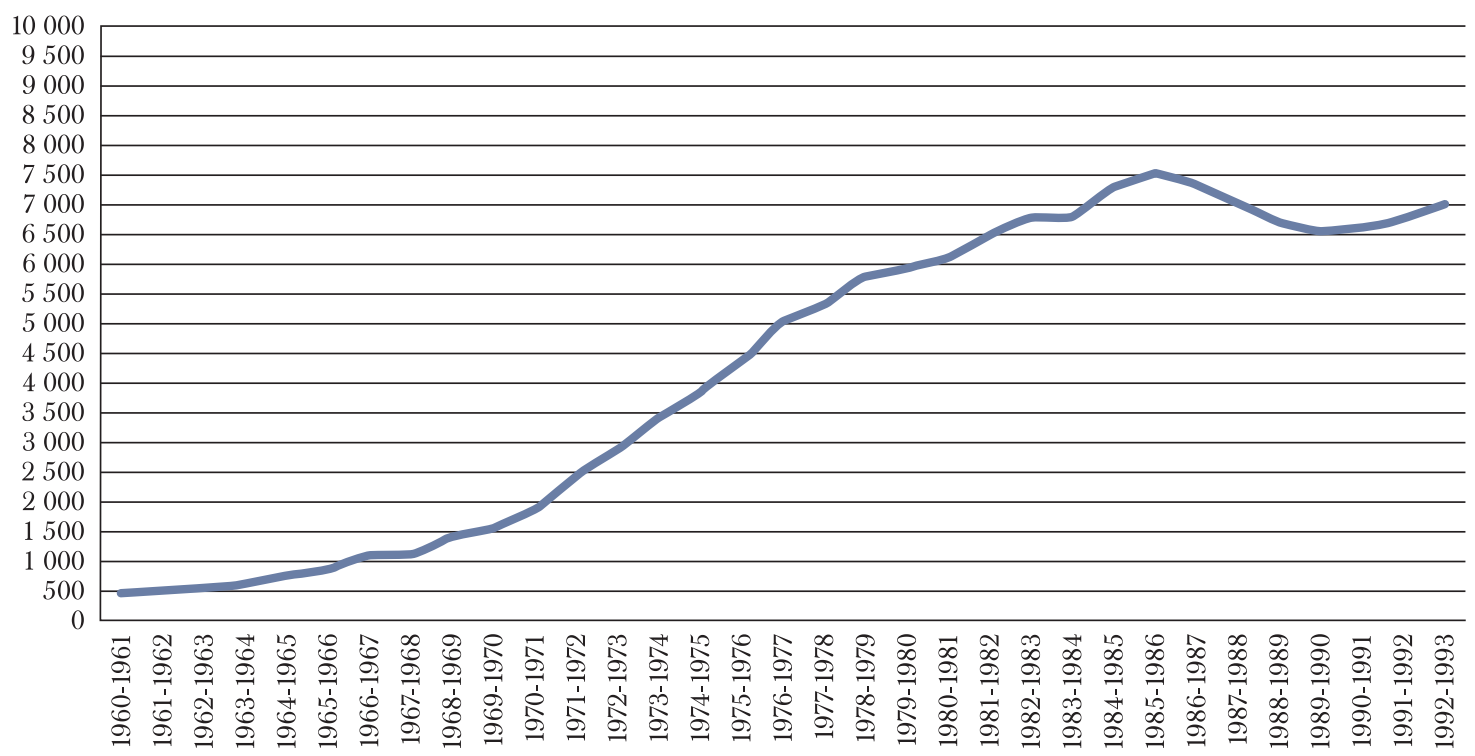

Fuente: elaboración propia con base en Universidad Autónoma de Yucatán (1985, 1993).

ro, además, en este último intervalo inicia el proceso de diversificación industrial y agropecuaria, que responde, de alguna manera, a la liquidación de la industria henequenera (Lapointe, 2006, pp. 203-204; Ramírez, 2006, pp. 29-33; Vera, 1990, pp. 452-453). Así, el gobierno del estado impulsa la diversificación agrícola (citrícola), alienta la ganadería (bovino) y fomenta la pesca (Villanueva, 1990, pp. 194-201).

En respuesta a esta nueva orientación económica del estado, la universidad funda nuevas facultades ${ }^{8}$ Antropología, Arquitectura, Comercio y Administración, Economía, Matemáticas, Veterinaria y Psicología. Esta nueva oferta educativa responde a los nuevos proyectos de diversificación económica. Luego entonces, cuestiones multifactoriales explican el crecimiento extraordinario de la matrícula estudiantil entre estas fechas (explosión demográfica, urbanización, diversificación económica e incremento de la oferta educativa). ¿Cómo se insertó la población maya en estos nuevos espacios que se abrieron en la universidad? Para estas fechas el contexto era distinto: el nuevo discurso indigenista lo incluía en la sociedad, y el proceso de castellanización y educación rendía buenos frutos.

El análisis de la población indígena en México supone un enorme reto. El atributo común para definir a esta población es la lengua (Vázquez, 2013). En el caso de la población universitaria, el principal obstáculo para identificar este grupo étnico es la ausencia de variables, en los registros estadísticos universitarios, que permitan asir a esta población. En estas condiciones, hemos optado

\footnotetext{
${ }^{8}$ Véase Objetivo de la creación de la Escuela de Comercio y Administración: “impartir conocimientos de las disciplinas contables y jurídicas necesarias para promover una mejor administración en los negocios, de manera que el bienestar y que el progreso que impriman a ellos se refleje también en la prosperidad del Estado”, en http://www.contaduria.uady.mx/who-info.php?id=eca [Consulta: 11 de noviembre de 2016.]
} 
por un atributo alternativo que nos acerque a la población maya en la Universidad de Yucatán: el apellido. Si bien esta propiedad como indicador de la población maya y no maya puede ser cuestionable, nos ofrece, indudablemente, un acercamiento a la población que tiene raíces indígenas.

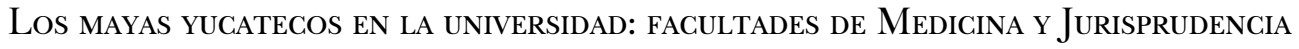

Las dos facultades más antiguas de la Universidad, Medicina y Jurisprudencia (posteriormente Derecho), son las que registran mayor número de estudiantes. Sin embargo, las fuentes no son homogéneas. La Facultad de Medicina es la que tiene información seriada que proviene de los libros de inscripciones, pero se interrumpe al inicio de la década de 1970, aunque hemos obtenido datos de otras fuentes (Cárdex, 1960-1988 9 no tienen la misma consistencia que las primeras, pero son una buena muestra. En el caso de la Facultad de Derecho, las cifras las extrajimos de los expedientes de los alumnos titulados e inician en la década de 1960. A pesar de todo, la evidencia recopilada nos da un buen pulso del ritmo de la incorporación de la población maya a los estudios superiores. Iniciemos con la Facultad de Medicina, que es la que nos proporciona información consistente para los primeros años (véase cuadro 2).

La población indígena inició su camino en la Facultad de Medicina prácticamente a partir de la década de 1950, fecha en que se inscriben los primeros estudiantes con los dos apellidos mayas. Para el siguiente decenio la población maya inscrita en la facultad creció con dinamismo hasta alcanzar en la década de 1970 el punto más alto; aunque en los ochenta continuó en ascenso la cantidad de estudiantes mayas que ingresaron a la carrera de médico, el ritmo fue mucho menor en relación con lo observado en las dos décadas anteriores, pues sólo creció $4 \%$ respecto a la década de 1970 (véase gráfica 5). Como hemos indicado en el caso del crecimiento general de la matrícula universitaria, este aumento de la población estudiantil maya en la Facultad de Medicina se asocia a la presión demográfica y urbanización.

Pero las cifras cobran otro sentido si se compara con el total de la población inscrita en esos años. Para la década de 1950, los mayas que solicitaron inscribirse en la Facultad de Medicina rondó en $5 \%$ del total, en la siguiente década el porcentaje creció $10 \%$. Para las décadas 1960 y 1970 el porcentaje prácticamente se mantiene estable (9 y $14 \%$, respectivamente). Por tanto, aquel incremento de la población maya en esta facultad se vuelve relativo cuando se contrasta con el crecimiento de la matrícula total, pues la proporción se mantuvo constante, a pesar del acelerado crecimiento de la población universitaria observado en estas mismas décadas.

$\mathrm{Al}$ observar las cifras, se aprecia que existen mecanismos de exclusión. Durante las tres primeras décadas del siglo xx ninguna persona con los dos apellidos mayas estudió en las aulas de la Facultad de Medicina. Es a partir de la década de 1940 cuando inicia el caminar de individuos con raíces mayas en la Universidad de Yucatán, pero las personas con los dos apellidos mayas fueron menores a los que tenían un solo apellido maya. Y más aún, aquellos individuos que tenían el apellido materno en maya tuvieron mayor acceso. En otras palabras, las personas que tenían el primer apellido en español y el segundo en maya son las que accedieron en mayor medida; una cuestión que entremezcla el peso de una sociedad patrilineal, la cuestión étnica y la importancia de la descendencia familiar en el acceso a los recursos (como la educación). 10 Lo anterior nos per-

\footnotetext{
${ }^{9}$ Son fichas que sintetizan el historial del estudiante en su tránsito por la carrera, entre los datos que contiene están: nombre, edad, lugar de nacimiento, fecha de ingreso y egreso, calificaciones, entre otros.

${ }^{10}$ Sobre las relaciones de parentesco véase Wolf (2005).
} 
GRÁFICA 5. ESTUDIANTES CON APELLIDOS MAYAS EN LA FACULTAD DE MEDICINA, 1920-1988

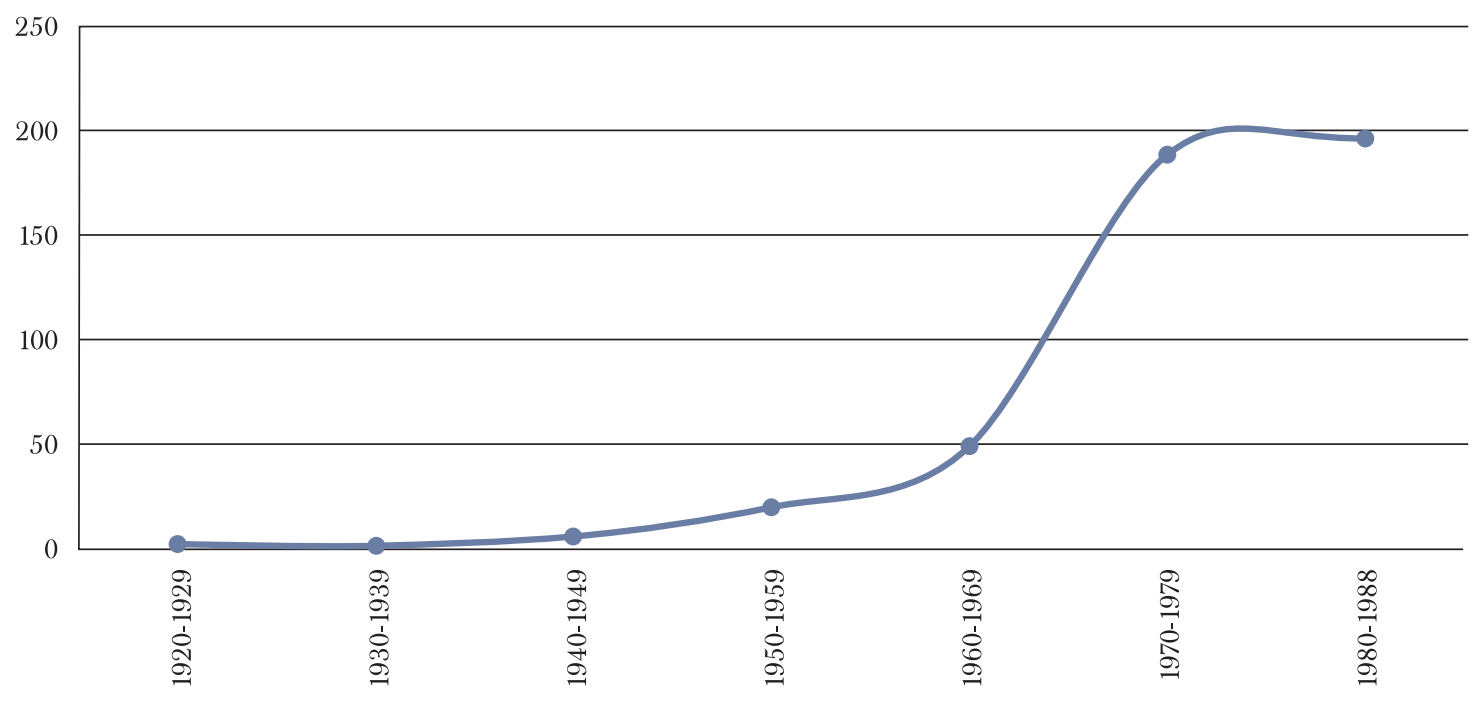

Fuente: véase cuadro 2

mite plantear la hipótesis de que no fue el apellido maya el que abrió las puertas de la universidad, sino el idioma español, es decir, la universidad dejó pocos espacios para aquellos descendientes directos de la etnia maya (con dos apellidos en maya). Ahora revisemos el comportamiento de las cifras para la Facultad de Derecho.

En el caso de la Facultad de Derecho las cifras corresponden a los estudiantes titulados a partir de 1960. Es importante aclarar que para fines comparativos los datos fueron ordenados de acuerdo con el primer año en que cursaron el primer grado de la carrera, fecha que no necesariamente se corresponde con el año de inscripción (véase cuadro 3 ).

En la década de 1960 inició el curso para los primeros mayas que se titularon en la Facultad de Derecho. La tendencia del crecimiento de la población es similar al de la Facultad de Medicina, ya que a partir de la década de 1970 vemos un ascenso positivo que encontrará su año de mayor crecimiento en la década de 1980. En cuanto al porcentaje de la población con apellidos mayas, es importante destacar que en esta institución la proporción es ligeramente superior: en los setentas se registra $15 \%$ y en la década siguiente, $21 \%$ respecto a la población total titulada. Pero existe una diferencia respecto a la Facultad de Medicina que importa destacar. En la década de 1980, en la distinción por apellidos se guarda cierto equilibrio, aunque es ligeramente menor el número de estudiantes con los dos apellidos mayas; pero esta pequeña diferencia nos permite argumentar que la Facultad de Derecho fue una opción más viable para los mayas yucatecos que la carrera de medicina. Pero también se puede concluir que la carrera de médico fue más excluyente que la de Derecho.

En otro orden de ideas, en el cuadro 4 podemos visualizar a tres cohortes o generaciones de estudiantes de Medicina, corresponden a las listas de alumnos inscritos a cada uno de los seis cursos en el periodo de 1980-1988. 


\section{CUADRO 2. ESTUDIANTES CON APELLIDOS MAYAS EN LA FACULTAD DE MEDICINA, 1920-1988}

\begin{tabular}{lrrrrr}
\hline Años & $\begin{array}{c}\text { Dos apellidos } \\
\text { mayas }\end{array}$ & $\begin{array}{c}\text { Apellido } \\
\text { paterno }\end{array}$ & $\begin{array}{c}\text { Apellido } \\
\text { materno }\end{array}$ & $\begin{array}{c}\text { Tasa de } \\
\text { crecimiento }\end{array}$ \\
\hline $1920-1929$ & 0 & 2 & 0 & 2 & \\
$1930-1939$ & 0 & 1 & 0 & 1 & -50 \\
$1940-1949$ & 0 & 4 & 2 & 6 & 500 \\
$1950-1959$ & 4 & 7 & 9 & 20 & 233 \\
$1960-1969$ & 7 & 17 & 25 & 49 & 145 \\
$1970-1979$ & 29 & 74 & 85 & 188 & 284 \\
$1980-1988$ & 34 & 72 & 90 & 196 & 4 \\
\hline
\end{tabular}

Fuente: Libros de inscripciones, Facultad de Medicina, Universidad Autónoma de Yucatán, y Cárdex (1960-1988).

\section{CUADRO 3. POBLACIÓN MAYA TITULADA EN LA FACULTAD DE DERECHO SEGÚN EL AÑO DE SU PRIMER GURSO, 1960-1989}

\begin{tabular}{lrrrr}
\hline Años & Apellidos mayas & Apellido paterno & Apellido materno & Total \\
\hline $1960-1969$ & 1 & 5 & 7 & 13 \\
$1970-1979$ & 15 & 41 & 47 & 103 \\
$1980-1989$ & 123 & 175 & 165 & 463 \\
\hline
\end{tabular}

Fuente: Expedientes, Facultad de Derecho, Universidad Autónoma de Yucatán.

El porcentaje de estudiantes en cada una de las generaciones se mantiene constante a lo largo del periodo la etapa (18 y $20 \%$ ). Existen pequeñas variaciones. En la generación (1980-1986) la población maya oscila entre 16 y $18 \%$, movimientos que muestran las deserciones y reincorporaciones durante una generación; la generación 1981-1987 es inestable, en tanto que en el tercer año esta cohorte decreció considerablemente. Así, se concluye que el nivel de eficiencia terminal de la población maya en la Facultad de Medicina es satisfactorio.

Por otra parte, el porcentaje de la población estudiantil de la Facultad de Medicina no maya oscila entre 80 y 82 \%, es decir, ocho de cada diez estudiantes de la Facultad de Medicina no tiene apellido maya, lo que nos indica que en la década de 1980 la población maya en la Facultad de Medicina continuó creciendo, pero a pesar de ello, las cifras revelan que la paridad distaba mucho de ser una realidad; por tanto, podemos concluir que para estas fechas era reducido el número de mayas yucatecos que accedían a los estudios universitarios.

Estas cohortes se vieron envueltas en la crisis económica y financiera nacional que impactó en el crecimiento económico y que tuvo, como hemos visto en párrafos anteriores, efectos negativos en el crecimiento de la población universitaria, ¿cómo impactó este fenómeno a la población maya de la Facultad de Medicina? (véase cuadro 5 .

Carecemos de cifras para hacer una comparación del comportamiento de las generaciones de estudiantes previo a la crisis. Las generaciones de 1980 a 1988 comparten la característica de haber cursado sus estudios en el momento de la crisis económica. Podemos partir del hecho de la 


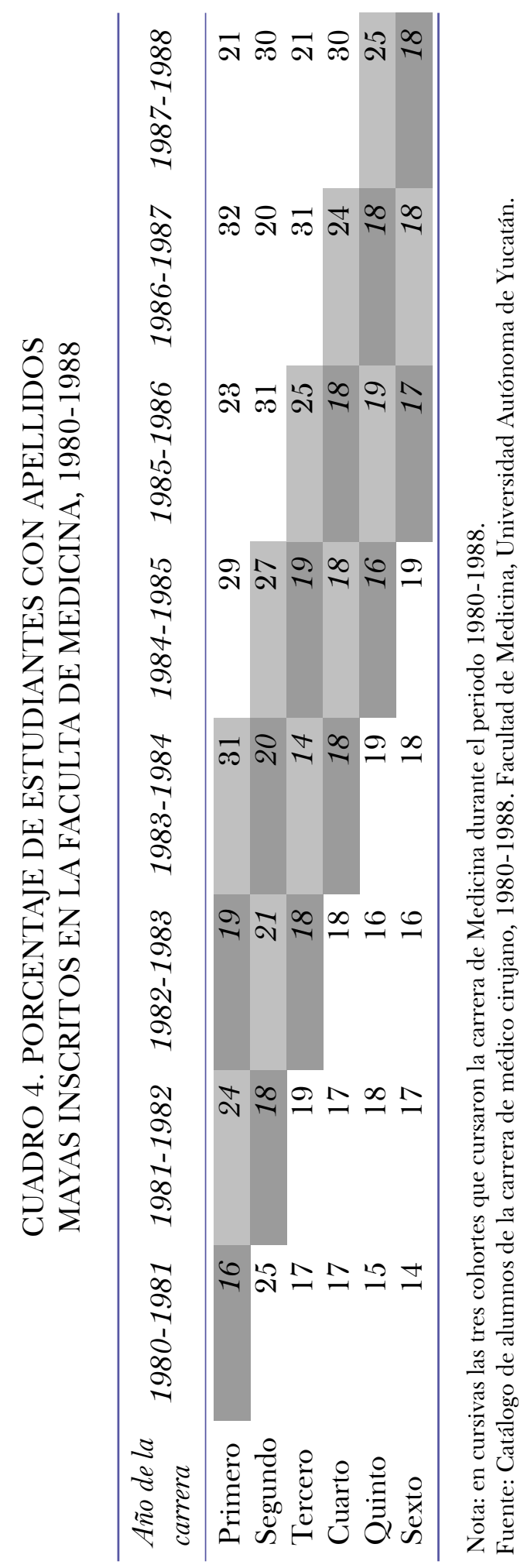




\section{GUADRO 5. TASA DE EFICIENCIA TERMINAL Y DESERCIÓN DE GUATRO GENERACIONES DE ALUMNOS DE LA FACULTAD DE MEDICINA, 1980-1988}

\begin{tabular}{llllll}
\hline \multirow{2}{*}{ Cohortes } & \multicolumn{3}{c}{ Mayas } & \multicolumn{3}{c}{ No mayas } \\
& TGET & TET & TD & TET & TD \\
\hline $1980-1986$ & 69 & 75 & 25 & 68 & 32 \\
$1981-1987$ & 62 & 54 & 46 & 88 & 22 \\
$1982-1988$ & 70 & 68 & 32 & 81 & 29 \\
$1983-1988$ & 59 & 48 & 52 & 64 & 36 \\
\hline
\end{tabular}

Nota: La última generación corresponde únicamente a cinco años, a pesar de que le falta un año (la generación egresó en 1989) la hemos incluido porque refleja el impacto de la crisis. En términos estrictos las tasas de eficiencia terminal se estiman con ingresos y egresos. Nuestras listas siguen a estas generaciones hasta su último curso, pero no supone egreso. A pesar de ello, hemos tomado el primer y el último curso de cada generación como ingreso y egreso. TGET $=$ tasa general de eficiencia terminal, $\mathrm{TET}=$ tasa de eficiencia terminal, $\mathrm{TD}=$ tasa de deserción.

Fuente: Catálogo de alumnos de la carrera de médico cirujano, 1980-1988. Facultad de Medicina, Universidad Autónoma de Yucatán.

existencia de una tasa de deserción, que se puede atribuir a la capacidad de las instituciones educativas de retener a los estudiantes, a la capacidad de los estudiantes (aprovechamiento escolar), a problemas socioeconómicos, una mala decisión en la elección de carrera, problemas sociofamiliares, entre otros. Contrario a la deserción es la eficiencia terminal (Rodríguez y Hernández, 2008, pp. 4-7) 11

El porcentaje de eficiencia terminal en las universidades públicas fue, en 1984, de $57 \%$ de acuerdo con los cálculos de la Asociación Nacional de Universidades e Instituciones de Educación Superior (anuiEs), y para nuestro interés, el área de ciencias de la salud registra la mayor tasa de eficiencia terminal, entre 1980 y 1988 rondó entre 59 y $76 \%$. En términos generales el nivel de eficiencia terminal (TGET) de estas cuatro cohortes en la Facultad de Medicina es similar al de las cifras nacionales. Pero cuando miramos los datos desagregando a los mayas vemos que la crisis tuvo efectos distintos. De acuerdo con las cifras, la tasa de eficiencia terminal de la población maya sólo es superior a la no maya en la generación de 1980-1986, en las siguientes cohortes se reducirá constantemente el número de estudiantes mayas que concluirán la carrera de médico, y en la generación 1983-1988 tendrá su punto más bajo al finalizar sólo 48 \% de los estudiantes mayas que inició estudios con aquella cohorte, es decir, más de la mitad de los que iniciaron no se inscribió al último año de la carrera, lo que supone que abandonó los estudios o se rezagó. A diferencia de los estudiantes que no tenían algún apellido maya, en las generaciones de 1981-1987 y 1982-1988, más del $80 \%$ de los no mayas que formaron parte de aquellas generaciones concluyeron los estudios de la carrera, superando incluso la media nacional. Por todo lo anterior podemos concluir que el impacto de la crisis económica fue más agudo en la eficiencia terminal de la población maya. ¿Por qué la población maya universitaria fue más vulnerable a la crisis económica? Sin duda, la respuesta a esta interrogante cobra relevancia en la comprensión de los problemas que enfrentó la población maya en la Universidad de Yucatán, y las características socioeconómicas son variables para explicarlos; una de estas es la del servicio telefónico.

${ }^{11}$ Para una discusión de las fortalezas y debilidades de los estudios de eficiencia terminal, véase Martínez (2001). 
Los estudios sobre la correlación entre renta y difusión de la telefonía durante la primera mitad del siglo xx, en países de Europa, muestran que, salvo algunas excepciones, la correlación entre renta per cápita y servicio telefónico es positiva (Calvo, 2010, pp. 24-30). Esta correlación es posible constatarla en el caso de Yucatán. En sus inicios los servicios telefónicos fueron empleados para enlazar y comunicar al municipio de Progreso con la ciudad de Mérida, al comercio de esta ciudad, algunas haciendas henequeneras y a la selecta elite yucateca. Para inicios del siglo xx, los servicios telefónicos se habían extendido a unas cuantas poblaciones del interior del estado; no obstante, aquellas familias que contaban con el servicio particular continuaban siendo reducidas, una característica que se observa en la década de 1930 (Suárez, 1977, vol. 2, pp. 214-215; Compañía Telefónica y Telegráfica Yucateca, 1931). De lo anterior se deduce que la baja cobertura geográfica del servicio telefónico supondría una correlación negativa entre estatus económico y este tipo de servicio, pero también que mejores condiciones económicas podrían romper este obstáculo.

En esta misma década la empresa de teléfonos Ericsson inició sus operaciones en la ciudad de Mérida; sus afiliados era la población que tenía acceso a este servicio. Una ligera mirada al directorio telefónico de la ciudad de Mérida revela que este servicio fue ofrecido para Mérida y Progreso, lo que muestra el carácter cosmopolita del servicio telefónico y el mercado demandante: comercios, fábricas, oficinas de gobierno, el sector servicios (escuelas, médicos, abogados) y una selecta elite (Ericsson, S. A., 1932); esta última, un grupo de población en el que no encontramos a persona alguna con apellido indígena, lo que indica que este servicio lo disfrutaban aquellas personas con cierta posición económica. De ahí que el servicio telefónico es un buen indicador de diferenciación social; incluso entre la población universitaria (véase cuadro 6).

Las cifras revelan que los estudiantes de la Facultad de Medicina tienen diversos orígenes geográficos. En el rango de uno a cinco estudiantes (con apellido maya y sin este), se observa que estos tienen su lugar de nacimiento en 50 de los 105 municipios en el que está divido el estado de Yucatán 12 es decir, más de la mitad de los municipios aportó de uno a cinco estudiantes a la Facultad de Medicina. Pero esta amplia cobertura geográfica contrasta con la concentración que se observa en un municipio: Mérida, pues es el único que registró a más de 100 estudiantes mayas y no mayas durante el periodo. A pesar de que para la década de 1980 se haya ampliado la cobertura de los servicios educativos universitarios, residir en la ciudad fue un factor determinante para cursar estudios superiores. Una distribución que no debe sorprender, pues los espacios culturales e intelectuales tienden a concentrarse en ciertos lugares, en particular en las urbes capitales 13 como Mérida, lo que se traduce en una desventaja de la población rural frente a la urbana. ¿Cuáles eran las diferencias socioeconómicas entre los estudiantes urbanos y rurales?

Para la década de 1930 la cobertura del servicio telefónico era reducida, pero seguramente que para la segunda mitad del siglo xx esta tendencia había cambiado. Las cifras muestran que la cobertura mejoró considerablemente, pues al menos un estudiante de cada uno de los municipios del interior del estado registró número telefónico. Pero la diferencia entre lo rural y urbano vuelve a aflorar. Mientras en el interior del estado únicamente poco más de $30 \%$ de los estudiantes cuenta con servicio telefónico, en la ciudad de Mérida más de la mitad de estos disfrutaba de este servicio. Si nos detenemos a contrastar entre los municipios del ámbito rural y estudiantes mayas y no mayas, en el mejor de los casos la relación es de uno a dos, es decir, por cada dos estudiantes

\footnotetext{
${ }^{12}$ Es importante señalar que no todos los municipios aportaron estudiantes; nuestros registros muestran que los estudiantes provenían de poco más de 70 municipios.

${ }^{13}$ Para una propuesta de la distribución espacial de los centros culturales véase Altamirano (2013, pp. 135-139).
} 
CUADRO 6. PORCENTAJE DE ESTUDIANTES DE LA FACULTAD DE MEDICINA QUE REGISTRARON NÚMERO TELEFÓNICO, 1960-1988

\begin{tabular}{lrrrr} 
& \multicolumn{3}{c}{ Mayas } & No mayas \\
Rango de estudiantes & Número de municipios & PET & Número de municipios & PET \\
\hline $1-5$ & 56 & 21 & 54 & 36 \\
$6-10$ & 7 & 12 & 8 & 30 \\
$11-20$ & 3 & 10 & 8 & 30 \\
$21-50$ & 2 & 11 & 3 & 26 \\
$50-100$ & 0 & 0 & 3 & 40 \\
101 y más & 1 & 30 & 1 & 57 \\
\hline
\end{tabular}

PET $=$ porcentaje de estudiantes con teléfono.

Fuente: Universidad Autónoma de Yucatán, Facutlad de Medicina, Cárdex 1960-1988.

rurales no mayas que registraron número telefónico, lo hizo uno con apellidos mayas. Un signo de la desigualdad económica de la población rural maya, y no sólo la rural, sino también en el caso del ámbito urbano.

Como hemos apuntado párrafos arriba, estas diferencias socioeconómicas han sido clave para explicar la eficiencia terminal, por tanto, una variable crucial en la explicación del desempeño académico de la población maya en la Universidad de Yucatán. Un factor que nos ayuda a explicar el impacto negativo de la crisis económica sobre la población maya en los estudios superiores, pues seguramente tenía condiciones económicas que la hicieron más vulnerable a la crisis económica.

Ahora analicemos las actividades económicas de los padres o tutores de la población maya que ingresó a la universidad. Pierre Bourdieu (2013) ha mostrado la importancia de las diferencias sociales y el grupo de origen como un elemento que influye en la forma en la que los individuos se relacionan con el medio escolar y con la cultura que transmite; esto es, la "distancia que hay entre su medio familiar y el universo escolar" como elemento explicativo de los llamados estudiantes prodigio o talento; que no son más - de acuerdo con Bourdieu- que personas que disfrutan de una posición ventajosa frente a la herencia o privilegio cultural. Son individuos que desde el seno familiar tuvieron la oportunidad de tener contacto con la cultura universitaria de manera inconsciente y que los dispone para los estudios universitarios. Estos antecedentes familiares son cruciales en el éxito escolar (Bourdieu, 2013, pp. 37-43), y son producto de una situación económica ventajosa, de hecho, muchos de sus padres tienen antecedentes escolares. El cuadro 7 sistematiza la información de los expedientes de los estudiantes titulados de la Facultad de Derecho en relación con la actividad económica de los padres de los estudiantes con apellidos mayas.

Como se puede apreciar, 28 de 77 municipios aportaron estudiantes a la Universidad de Yucatán cuya totalidad de los padres desarrollaban actividades primarias, esto es, de $21 \%$ de estos lugares salieron mayas yucatecos con padres o tutores dedicados a las actividades primarias, se registraron como agricultores, ejidatarios, peones de campo, cordeleros, pescadores, entre otros; actividades económicas que están estrechamente vinculadas al medio rural. En términos generales, en poco menos de la mitad de los 77 municipios (34), siete de cada diez padres de los estudiantes mayas eran agricultores o desempeñaban una actividad primaria. Las cifras sin duda revelan las condiciones económicas en las que se encontraban los mayas yucatecos que accedieron a la univer- 


\section{CUADRO 7. PORCENTAJE DE PADRES OCUPADOS SEGÚN ACTIVIDAD ECONÓMICA (FACULTAD DE DERECHO), 1960-1980}

\begin{tabular}{lrrrr}
\hline $\begin{array}{l}\text { Rango de porcentaje } \\
\text { de padres }\end{array}$ & Primario & $\begin{array}{c}\text { Número de municipios } \\
\text { Secundario }\end{array}$ & Terciario & Profesional \\
\hline 91 a 100 & 28 & 7 & 1 & s. d. \\
81 a 90 & 3 & 1 & 0 & s. d. \\
71 a 80 & 3 & 1 & 0 & s. d. \\
61 a 70 & 5 & 4 & 0 & s. d. \\
51 a 60 & 13 & 3 & 0 & s. d. \\
41 a 50 & 3 & 9 & 2 & 1 \\
Menos de 40 & 10 & 12 & 4 & 8 \\
\hline
\end{tabular}

Fuente: Universidad Autónoma de Yucatán, Expedientes.

sidad. El problema se acentúa si miramos las actividades secundarias y vemos la baja concentración de municipios en este sector, mucho más ilustrativo es el rubro de las actividades terciarias y el escaso número de padres en este sector.

Este contexto de padres trabajando en actividades primarias y en el medio rural hace patente el nulo acceso de estos a los estudios superiores o carreras profesionales y, siguiendo a Bourdieu, ahondan las desventajas de los mayas yucatecos en el ámbito de la Universidad de Yucatán. Lo anterior explica el escaso número de padres de estudiantes mayas que declararon ser profesionales (ocho personas); la dimensión de esta cifra es considerable si partimos del hecho de que los mayas yucatecos titulados en la Facultad de Derecho son de 700 estudiantes mayas, es decir, prácticamente uno de cada 100 estudiantes mayas declaró tener padre con estudios profesionales.

\section{Conclusiones}

La Universidad Nacional del Sureste nació a principios del siglo xx en un contexto que tenía en mente un cambio político en relación con la etnia maya. Una población que para aquellas fechas formaba un grupo que, en proporción, era superior a la no maya. Las diversas políticas para crear una nación mexicana sin identidad étnica excluyeron a la población maya de diversos espacios políticos, económicos y culturales, entre ellos la universidad. Pero con el transcurrir de los años las diversas políticas de unificación étnica y lingüística tuvieron los efectos buscados al reducir el número de hablantes mayas, pero lejos de borrarlos, el crecimiento sostenido del bilingüismo pone en duda el éxito de las políticas lingüísticas y muestra la capacidad de la etnia maya de mantener el lenguaje como el signo más importante de su identidad.

Pero quizá sea esta identidad la que continuó marginando a la población maya de la universidad. No obstante sus inicios, el crecimiento de la población universitaria fue un fenómeno constante, la población estudiantil con apellidos mayas en la universidad tiene su aparición a partir de la segunda mitad del siglo xx. En esa misma dirección, a partir de la década de 1960 se observa, como en otros ámbitos nacionales, el fenómeno de la masificación de los estudios superiores; pero 
este crecimiento inusitado de la población escolar universitaria no tuvo los mismos efectos sobre la población con apellidos mayas, el ritmo de incorporación es inferior a los estudiantes con apellidos no mayas.

Esta exclusión tiene varias explicaciones, la que hemos analizado líneas arriba es la vulnerabilidad económica de la población maya frente a las crisis económicas, una desventaja que se explica por la diferenciación socioeconómica que se refleja en la actividad económica de los padres de los mayas universitarios que se empleaban en actividades del sector primario, particularmente en la agricultura de subsistencia. Además, un alto porcentaje de esta población provenía del medio rural, lo que la hacía aún más endeble. Si bien es cierto que toda la población universitaria resentía los efectos de las crisis económicas, la población maya era más sensible a ella, y es un elemento clave para explicar el rendimiento escolar. Otro de los factores clave en esta explicación es sin duda los antecedentes escolares en el ámbito doméstico. Ha quedado patente que los padres de los mayas yucatecos que accedieron a los estudios universitarios hasta la década de 1980 tenían prácticamente nulos antecedentes académicos. Ante estos datos duros no queda duda de los problemas que enfrentó la población maya yucateca en el ámbito universitario. Sin embargo, falta por explicar todos aquellos elementos subjetivos que están presentes en el espacio y discurso público y, que, sin duda, tienen un efecto directo en la decisión de cursar los estudios superiores.

\section{LISTA DE REFERENCIAS}

Acevedo, A. (2011). La ignorada cuestión del lenguaje: educación en los pueblos indígenas de Puebla. En M. de L. Alvarado y R. Ríos (eds.), Grupos marginados de la educación: siglos XIX y XX (pp. 431-460). México: Universidad Nacional Autónoma de México.

Aguirre, G. M. E. (2016). Historia e historiografía de la educación en México hacia un balance, 20022011. Recuperado de http://publicaciones.anuies.mx/pdfs/libros/Libro224.pdf

Aguirre, R. (2011). Algunas problemáticas sociales del estudiantado de la Real Universidad de México en el siglo xviII. En M. de L. Alvarado y R. Ríos (eds.), Grupos marginados de la educación: siglos XIX y XX (pp. 135-158). México: Universidad Nacional Autónoma de México.

Altamirano, C. (2013). Intelectuales: notas de investigación sobre una tribu inquieta. Buenos Aires: Siglo XXI Editores.

Amaro, J. (1984). El uayeísmo en la cultura de Yucatán. México: Instituto Politécnico Nacional/Universidad Autónoma de Yucatán.

Arrigunaga y Peón, J. de (1975). Españoles, mestizos e indios, forjadores de la intelectualidad yucateca 1722-1860 (vol. 2). Yucatán: Academia Yucateca de Historia y Genealogía Francisco de Montejo.

Baqueiro, S. (1894). Historia del Antiguo Seminario Conciliar de San Ildefonso. Yucatán: Tipografía G. Canto.

Barreyro, G. B. (2008). La educación superior en Brasil: raza, renta y escuela media como factores de desigualdad. Revista de la educación superior, 37(146), 53-64.

Bourdieu, P. (2013). La nobleza de Estado: educación de elite y espíritu de cuerpo. Argentina: Siglo XXI Editores.

Bracamonte, P. (2007). Una deuda histórica. Ensayo sobre las condiciones de pobreza secular entre los mayas de Yucatán. México: Centro de Investigaciones y Estudios Superiores en Antropología Social/Porrúa.

Brambila, C. (1992). Expansión urbana en México. México: El Colegio de México. 
Calvo, Á. (2010). Historia de Telefónica, 1924-1975: primeras décadas: tecnología, economía y política. En Fundación Telefónica. Libro: Vol. 7. Recuperado de https://www.fundaciontelefonica.com

Campo, O. del y Salcines, J. V. (2008). El valor económico de la educación a través del pensamiento económico en el siglo XX. Revista de la Educación Superior, 37(3), 45-61.

Casillas, M., Chain, R. y Jácome, N. (2007). Origen social de los estudiantes y trayectorias estudiantiles en la Universidad Veracruzana. Revista de la educación superior, 36(142), 7-29.

Cobá, L. (2017). La educación superior y el indio maya yucateco: siglos XVII y XVIII. En J. I. Castillo, R. Domínguez y J. E. Serrano (eds.), Historia de la educación superior en Yucatán: las instituciones (universidad, colegio e instituto), siglos XIX y XX. Yucatán: Universidad Autónoma de Yucatán.

Compañía Telefónica y Telegráfica Yucateca. (1931). Directorio de la Compañía Telefónica y Telegráfica Yucateca, S. A. Mérida: Compañía Telefónica y Telegráfica Yucateca.

Cook, S. F. y Borah, W. W. (1978). Ensayos sobre historia de la población: México y El Caribe (C. Zmora, trad.). México: Siglo XXI.

Domínguez, A. (2012). Educación y poder en Nueva España: los colegiales reales de San Ildefonso, 16231767 (Tesis de maestría), Universidad Nacional Autónoma de México, México. Recuperado de http://132.248.9.195/ptd2013/Presenciales/0702357/Index.html

Ericsson, S. A. (1932). Lista provisional de abonados. Empresa de teléfonos Ericsson, S. A. Sucursal en Mérida. Recuperado de http://www.aleph.org.mx/jspui/bitstream/56789/32078/8/1006b_ 08_Capitulo_8.pdf

Flores, J. (2010). Crecimiento económico e indicadores de bienestar social en México, 1950-2008. En J. Flores (ed.), Crecimiento y desarrollo económico de México (pp. 61-90). México: Universidad Autónoma Metropolitana.

Gallo, M. E. (2005). Masificación de la educación superior: una reflexión acerca de sus causas y contradicciones. Faces, 11(22), 49-64.

Giraudo, L. (2010). De la ciudad "mestiza” al campo "indígena”: internados indígenas en el México posrevolucionario y en Bolivia. Anuario de Estudios Americanos, 67(2), 519-547. DOI: 10.3989/aeamer.2010.v67.i2.518

Knight, A. (2013). Repensar la Revolución mexicana (vol. 2). México: El Colegio de Mexico.

Lapointe, M. (2006). Historia de Yucatán, siglos XIX-XXI. Yucatán: Universidad Autónoma de Yucatán.

Lapointe, M. y Dufresne, L. (1990). El cardenismo en Yucatán. En O. Baños (ed.), Sociedad, estructura agraria y estado en Yucatán (pp. 341-378). Yucatán: Universidad Autónoma de Yucatán.

Levy, D. C. (1995). La educación superior y el Estado en Latinoamérica: desafíos privados al predominio público. En Colección Problemas educativos de México. México: Universidad Nacional Autónoma de México.

Marsiske, R. (1998). Los estudiantes: trabajos de historia y sociología. México: Universidad Nacional Autónoma de México.

Marsiske, R. (2011). Estudiantes universitarios y revolución mexicana: de la elite cultural a la elite política y económica. En L. Alvarado y R. Ríos (eds.), Grupos marginados de la educación: siglos XIX y Xx. México: Universidad Nacional Autónoma de México.

Martínez, F. (2001). Estudio de la eficiencia en cohortes aparentes. En R. Chaín (ed.), Deserción, rezago y eficiencia terminal en las IES. Propuestas metodológicas para su estudio. México: ANUIES.

Menegus, M. y Aguirre, R. (2006). Los Indios, el sacerdocio y la universidad en Nueva España, siglos XVI-XVIII. En Historia. México: Universidad Nacional Autónoma de México/Plaza y Valdés. 
México. Departamento de Estadística Nacional (1928). Censo General de Habitantes. Estado de Yucatán. 30 de noviembre de 1921. México: Secretaría de la Economía Nacional. Recuperado de http://internet.contenidos.inegi.org.mx/contenidos/productos/prod_serv/contenidos/espanol /bvinegi/productos/censos/poblacion/1921/yuc/CGHEYUC21I.pdf

México. Dirección General de Estadística (1934). Quinto censo de población: 15 de mayo de 1930 [vol. 8, t. 31]. México: Secretaría de Economía Nacional.

Mexico. Dirección General de Estadística (1943). Sexto censo de poblacion, 1940. Yucatán. México: Secretaría de Economía Nacional.

Mexico. Dirección General de Estadística (1953). Septimo censo general de poblacion, 6 de Junio de 1950: resumen general. Mexico: Secretaría de Economía Nacional.

Mexico. Dirección General de Estadística (1963). Octavo censo general de poblacion, 1960: 8 de junio de 1960: estado de Yucatan. México: Secretaría de Economía Nacional.

México. Dirección General de Estadística (1971). Noveno censo general de poblacion, 1970, 28 enero de 1970. Mexico: Secretaría de Economía Nacional.

México. Instituto Nacional de Estadística, Geografía e Informática (1983). Décimo censo general de población y vivienda, 1980: estado de Yucatán. México: INEGI.

Mungaray, A. y Torres, V. H. (2010). Actividad económica y educación superior en México. Revista de la educación superior, 39(156), 7-18.

Rabell, C. y Mier y Terán, M. (1986). El descenso de la mortalidad en México de 1940 a 1980. Estudios Demográficos y Urbanos, 1(1), 39. DOI: 10.24201/edu.v1i1.569

Ramírez Carrillo, L. A. (2006). Mérida: una modernidad inacabada: un siglo de población y empleo urbano. Mérida: Fundación Plan Estratégico de Mérida.

Ramírez, L. A. (1993). Sociedad y población urbana en Yucatán, 1950-1989. México: El Colegio de México.

Ríos, R. (2011). Reflexiones sobre la problemática de la educación superior de los indígenas en la primera mitad del siglo XIX. Un acercamiento historiográfico. En M. L. de Alvarado y R. Ríos Zúñiga (eds.), Grupos marginados de la educación: siglos XIX y XX. México: Universidad Nacional Autónoma de México.

Rodríguez, J. y Hernández, J. M. (2008). La deserción escolar universitaria en México. La experiencia de la Universidad Autónoma Metropolitana, Campus Iztapalapa. Actualidades Investigativas en Educación, 8(1), 1-30. DOI: 10.15517/aie.v8i1.9308

Sandoval, G. y Mantilla, J. (1994). Felipe Carrillo Puerto: ensayo biográfico (vida y obra). Yucatán: Universidad Autónoma de Yucatán.

Schmelkes, S. (2013). Educación de los pueblos indígenas: problemas de medición. Realidad, Datos y Espacio. Revista Internacional de Estadística y Geografía, 4(1). Recuperado de http://www.inegi.or g.mx/RDE/2013/01/10/

Smith, A. D. (2004). Nacionalismo: teoría, ideología, historia (O. Bernárdez, Trad.). Madrid: Alianza. Spencer, D. (1990). La política económica del socialismo en la frontera sur, 1918-1923. En O. Baños (ed.), Sociedad, estructura agraria y estado en Yucatán (pp. 323-340). Yucatán: Ediciones de la Universidad Autónoma de Yucatán.

Suárez, V. M. (1977). La evolución Económica de Yucatán. A través del Siglo XIX. Yucatán: Universidad Autónoma de Yucatán.

Torres, R. (2013). Colegios regulares y seculares de Puebla y la formación de las elites letradas en el siglo XVIII (Tesis de doctorado). Universidad Nacional Autónoma de México, México. Recuperado de http://132.248.9.195/ptd2013/mayo/0693814/Index.html 
Universidad Autónoma de Yucatán (1985). Información estadística. Ciclos escolares, 1960-1961/19841985. Mérida: Autor.

Universidad Autónoma de Yucatán (1993). Anuario estadístico. Yucatán: Autor.

Vázquez, G. (2013). Dinámica demográfica de las poblaciones indígenas en México: 1970-2010. En M. Ordorica y L. M. Valdés (eds.), Hacia una nueva ley general de población (pp. 237-258). México: Universidad Nacional Autónoma de México.

Vera, T. (1990). Las transformaciones de la estructura socioeconómica de Yucatán en el contexto del desarrollo capitalista del sureste a partir de la posguerra. En O. Baños Ramírez (ed.), Sociedad, estructura agraria y estado en Yucatán (pp. 433-478). Yucatán: Universidad Autónoma de Yucatán.

Villanueva, E. (1990). La formación de las regiones en Yucatán. En O. Baños (ed.), Sociedad, estructura agraria y estado en Yucatán (pp. 167-204). Yucatán: Universidad Autónoma de Yucatán.

Wolf, E. (2005). Relaciones de parentesco, de amistad y de patronazgo en las sociedades complejas. En J. Vendrell (comp.), Teoría social e historia. La perspectiva de la antropología social. México: Instituto de Investigaciones Dr. José María Luis Mora.

Zapata, C. (2009). Indígenas y educación superior en América Latina: los casos de Ecuador, Bolivia y Chile. ISEES: Inclusión Social y Equidad en la Educación Superior, 5, 71-97.

Hemerografía

Boletín de la Universidad Nacional del Sureste, años 1922-1930. Yucatán, México.

Orbe. Órgano de la Universidad Nacional del Sureste, años 1938, 1949. Yucatán, México. 